\title{
Co-occurrence of Gilbert's syndrome and psychosis
}

\author{
A. S. Mahdi and M. S. Elameer
}

\begin{abstract}
Idlopathic unconjugated hyperbilirubinaemia (Gilbert's syndrome) is a common benign disorder that, when seen in association with psychiatric ilinesses, often leads to the inappropriate withholding of psychotropic medication. We describe three cases with Gilbert's syndrome and psychosis in which diagnosis of Gilbert's syndrome was delayed. This led to unnecessary investigations, further relapses and increased admisstons to hospltal. We emphasise the need for psychiatrists to be more aware of this benign condition.
\end{abstract}

Hereditary gluconosyl transferase deficiency (Gilbert's syndrome) was originally reported by Gilbert \& Lereboullet (1901). Since then there has been increasing recognition of this benign chronic disorder. It is relatively common, the incidence in the general population being reported as about 3-7\% (Blanckaert \& Fevery, 1990), and mainly affects males between 20 and 40 years of age (Taylor, 1984).

It is characterised by mild persistent unconjugated hyperbilirubinaemia, the patient often being unaware of the condition until it is detected by physical examination or routine laboratory testing. Patients with Gilbert's syndrome are found to have partial deficiency of gluconosyl transferase, which is important for removal of bilirubin by the liver through conjugation with glucotonic acid. This deficiency causes an increase in the level of unconjugated bilirubin (indirect) in comparison with conjugated (direct) bilirubin. The jaundice can fluctuate and may exacerbate following prolonged fasting, fever, infection, excess exertion or alcohol ingestion.

Diagnosis is mainly by exclusion, but should be suspected in a patient with:

(a) total serum bilirubin in the range 21 $51 \mu \mathrm{mol} / 1(1.2-3 \mathrm{mg} / \mathrm{dl})$ rarely exceeding $86 \mu \mathrm{mol} / 1(5 \mathrm{mg} / \mathrm{dl})$ and mostly of the unconjugated type (found following prolonged fasting or calorie depletion, $300 \mathrm{cal} /$ day for two days);

(b) no systemic symptoms;

(c) no overt or clinically recognised haemolysis;

(d) normal test of routine liver function.
Diagnosis is confirmed by reduced calorie intake or nicotinic acid provocation or bilirubin analysis with thin layer chromatographic methods (Davidson et al, 1975; Seig et al, 1986).

Gilbert's syndrome was reported in one case of manic-like psychosis and in another case of bipolar affective disorder (Loyd et al, 1982; Cohen \& Cohen, 1992). Durst et al (1993) described four cases of Gilbert's syndrome and concurrent psychiatric illnesses (schizoid personality disorder, endogenous depression and two cases of paranoid psychosis) where administration of psychotropic medication was undertaken and produced no adverse effects on hepatic function. They emphasised that psychotropic medication should be used whenever needed. Muller et al (1991) studied the bilirubin plasma concentration of 892 patients with psychiatric illness and found that $11 \%$ had raised levels. The levels were significantly higher in patients with schizophrenia $(25.4 \%)$ than in those with other diagnoses $(6.1-9.3 \%)$. They indicated that their findings were independent of drug usage and suggested a relationship between hyperbilirubinaemia and psychosis. Some hypotheses for the relationship were a possible genetic disposition for Gilbert's syndrome, increased vulnerability of red cell membranes or the role of oestrogen in schizophrenia.

We describe the clinical presentation of three psychiatric patients with Gilbert's syndrome, and the difficulties in their management that resulted.

\section{Case number 1}

Mr R.J. is a 37-year-old male with a history of schizotypal personality disorder. He has had several admissions to hospital, resulting from his withdrawn, uncommunicative and depressed behaviour and self-neglect. He was first found to have hyperbilirubinaemia (see Table 1) while he was being treated with $70 \mathrm{mg}$ lofepramine twice daily. He was referred to a consultant physician for a second opinion, where various investigations were done, including abdominal ultrasound, hepatitis screen, alpha antitrypsin level, serum copper and caeruloplasmin. It was 
concluded that he was suffering from liver damage secondary to antidepressant medication, and we were advised not to prescribe any antidepressants or drugs from the phenothiazine group. A very clear notification was placed on the front of his case notes advising that psychotropics should be avoided due to multiple allergy.

He was almost medication free for nearly four years, during which he was admitted three times and treated unsuccessfully with electroconvulsive therapy. His serum bilirubin remained elevated even when he was off medication. It was felt that a small dose of flupenthixol injection $20 \mathrm{mg}$ every two weeks might be beneficial. It was noticed that there was no further evidence of liver damage while he was on such medication. Unfortunately, the patient and his parents were reluctant to continue on medication, worrying that he was sensitive to drugs. On his last admission he presented with odd beliefs and behaviour and a history of discontinuation of his medication three months previously. The question of using psychotropic medication was raised again by the nursing staff in view of the notification in his case notes. He was again referred to the consultant physician who confirmed Gilbert's syndrome after measurement of total serum bilirubin before and after 24-hour fasting. The patient and parents were reassured about the benign nature of Gilbert's syndrome and the safety of the use of psychotropic medication. He was prescribed trifluoperazine $5 \mathrm{mg}$ twice daily and he showed a very good response.

\section{Case number 2}

Mr L.D. is a 26-year-old male diagnosed with paranoid schizophrenia at the age of 22 , when he was prescribed $50 \mathrm{mg}$ chlorpromazine three times daily. At follow-up he was noticed to be jaundiced and liver function tests showed total serum bilirubin $42 \mu \mathrm{mol} / 1$ direct less than $14 \mu \mathrm{mol} / 1$ (Table 1). Referral to a consultant physician resulted in a suggested diagnosis of Gilbert's syndrome and a recommendation that neuroleptic medication should be kept low and alternative psychiatric therapy used if possible. Chlorpromazine medication was discontinued and the patient showed a deterioration in his mental condition. He was referred again to a gastroenterologist who confirmed a diagnosis of Gilbert's syndrome and reassured us about the use of psychotropic medication. Medication was restarted and the patient and his father reassured that the condition was benign and medication safe and necessary.

\section{Case number 3}

Miss N.D. is a 30-year-old female who was diagnosed as having bipolar affective disorder at the age of 23. At that time she showed a good response to haloperidol $5 \mathrm{mg}$ daily, but after a few weeks of treatment she was noticed to have mild jaundice which was associated with diarrhoea, nausea and vomiting. Liver function tests showed high serum bilirubin, total serum bilirubin $23 \mu \mathrm{mol} / 1$, direct less than $11 \mu \mathrm{mol} / 1$ (Table 1) and because of this her medication was stopped. After a few months she was admitted to hospital with a relapse of her condition when she presented with delusions and hypomanic features. She was prescribed chlorpromazine $25 \mathrm{mg}$ four times daily. Her routine blood test showed that the serum bilirubin was shown to be raised. Other liver function tests were normal. She was referred to the consultant physician who suggested a diagnosis of Gilbert's syndrome and again this was confirmed by estimation of total serum bilirubin before and after 24-hour fasting. Taking the advice of the consultant physician, neuroleptics were prescribed whenever needed.

\section{Comment}

All three patients described in our study were diagnosed as having Gilbert's syndrome, mainly by estimation of total serum bilirubin before and after 24-hour fasting and persistent high level of indirect type bilirubin, while other liver function tests were normal.

The failure to diagnose Gilbert's syndrome at an early stage led to our patients having unnecessary and expensive investigations and inappropriate withdrawal of medication. The use of psychotropic medication is necessary in most cases of

Table 1. Liver function tests

\begin{tabular}{|c|c|c|c|c|c|c|c|}
\hline Case number & $\begin{array}{l}\text { Blinubin (total) } \\
(\mu \mathrm{mol} / \mathrm{l})\end{array}$ & $\begin{array}{l}\text { Bilinubin direct } \\
\text { (umol//) }\end{array}$ & $\begin{array}{l}\text { Alanine amino } \\
\text { transferase (u/l) }\end{array}$ & $\begin{array}{l}\text { ALK } \\
(U / D)\end{array}$ & $\begin{array}{l}\text { GT } \\
(u / 1)\end{array}$ & $\begin{array}{l}\text { Urea } \\
\text { (mmol/l) }\end{array}$ & $\begin{array}{l}\text { Creatinin } \\
\text { (umol/1) }\end{array}$ \\
\hline $\begin{array}{l}1 \\
2 \\
3 \\
\text { Normal levels' }\end{array}$ & $\begin{array}{l}27 \\
42 \\
23 \\
2-17\end{array}$ & $\begin{array}{l}<11 \\
<14 \\
<11 \\
0-10\end{array}$ & $\begin{array}{l}22 \\
17 \\
19 \\
0-40\end{array}$ & $\begin{array}{l}115 \\
144 \\
85 \\
90-280\end{array}$ & $\begin{array}{l}8 \\
12 \\
19 \\
11-50\end{array}$ & $\begin{array}{l}5.6 \\
2.7 \\
3.2 \\
1.7-6.0\end{array}$ & $\begin{array}{l}94 \\
85 \\
56 \\
53-115\end{array}$ \\
\hline
\end{tabular}

1. Normal level values from Biochemistry Laboratories at West Wales General Hospital (further details available from the author upon request). 
psychosis and unnecessary discontinuation in our cases led to relapses and further difficulties in management. Reintroduction of psychotropic medication decreased the incidences of relapses and confirmed the safety of neuroleptics in Gilbert's syndrome as suggested by others (Cohen \& Cohen, 1992; Durst et al, 1993).

Psychiatric illnesses are regarded as complex disorders: disorders which show evidence of gene effect but do not show clear Mendelian patterns of inheritance. Comorbidity of such illneses with other genetic disorders might be of help in understanding their psychopathology. A hypothetical explanation for the higher incidence of hyperbilirubinaemia and schizophrenia, genetic predisposition, was emphasised by Muller et al (1991). Further reporting of similar cases to the present study may emphasise the significant comorbidity of Gilbert's syndrome and mental disorder which will need further clarification.

\section{References}

Davidson. A. R., Rojas-Beuno, A.. Thompson, R. P. H., et al (1975) Reduced caloric intake of nicotinic acid provocation tests in the diagnosis of Gilbert's syndrome. British Medical Joumal. ii. 480.
Blanckaert. N. \& FeVery. J. (1990) Physiology and pathophysiology of bilirubin metabolism. In Hepatology: A Textbook of Liver Disease (eds T. Zakim \& T. D. Boyer) pp. 254-285. Philadelphia. PA: W. B. Saunders.

COHEN. L. S. \& COHEN, D. E. (1992) Lithium induced hyperbilirubinaemia in an adolescent. Journal of Clinical Psychopharmacology, 11, 274-275.

DURST, R., JABTINSKY-RUBIN. K.. DOREVITCH. A. et al (1993) Idiopathic unconjugated hyperbilirubinaemia (Gilbert's syndrome) and concurrent psychotropic drug administration. Pharmacopsychiatry. 26. 49-52.

GILBERT, A. \& LEREBOULLET, P. (1901) La cholemie simple familiale. Semaine Médicale, 21, 241-245.

LOYD, D. W. TsuAnG, M. T. \& BENGE, J. W. (1982) A study of a family with Leopard syndrome. Journal of Clinical Psychiatry. 43, 113-116.

Muller, N., SCHILleR, P. \& ACKenheIl, M. (1991) Coincidence of schizophrenia and hyperbilirubinaemia. Pharmacopsychiatry. 24. 225-228.

Seig. A.. Stich. A.. RAEDSCH. R., et al (1986) Gilbert's syndrome: diagnosis by typical serum bilirubin pattern. Clinical Chimica Acta, 184, 41-48.

TAnoR, S. (1984) Gilbert's syndrome as a cause of postoperative jaundice. Anaesthesia. 39. 1222-1224.

*A. S. Mahdi, Senior House Officer in Psychiatry. and M. S. Elameer, Consultant Psychiatrist, St David's Hospital, Carmarthen. Carmarthenshire. SA31 3HB

*Correspondence

\title{
Butterflies, fractals and psychiatry
}

\author{
Steven Reid
}

In this paper concepts related to the field of non-linear dynamics and choos theory are discussed, and their relevance to psychiatry is considered.

'In all chaos there is a cosmos, in all disorder a secret order' (Jung, 1954)

For many, chaos theory is a new branch of science that appears to involve the butterfly effect' and 'fractals', but which is little understood and has no obvious relevance to psychiatry. The purpose of this paper is to unravel a number of unfamiliar concepts, and describe some of the influences this emergent mathematical theory has had upon medicine and more specifically, psychiatry.
Previously the application of basic sciences to clinical medicine has relied upon linear, deterministic processes which were relatively easily understood and predictable. Classical determinism as propounded by Laplace, viewed the universe as a gigantic, intricate clockwork machine in which all events were predictable and the magnitude of any evoked response was proportionate to the size of its stimulus. However, there are physical systems which are seemingly non-linear and highly unpredictable such as turbulence in liquids (e.g. blood flow in the heart) and cerebral electrical activity. In these situations small changes can result in large and unanticipated effects. Since the 1960s, scientists from a variety of backgrounds have been attempting to provide models for this 